\section{BRAZILIAN JOURNAL \\ OF MEDICAL AND BIOLOGICAL RESEARCH}

www.bjournal.com.br
ISSN 1414-431X

Volume 45 (12) 1102-1340 December 2012

\section{BIOMIDICAL SCIENCES}

AND

CLINICAL INVESTIGATION

Braz J Med Biol Res, December 2012, Volume 45(12) 1295-1300

doi: 10.1590/S0100-879X2012007500161

Effect of heat and moisture exchangers on the prevention of ventilator-associated pneumonia in critically ill patients

M. Auxiliadora-Martins, M.G. Menegueti, E.A. Nicolini, G.C. Alkmim-Teixeira, F. BellissimoRodrigues, O.A. Martins-Filho and A. Basile-Filho

The Brazilian Journal of Medical and Biological Research is partially financed by

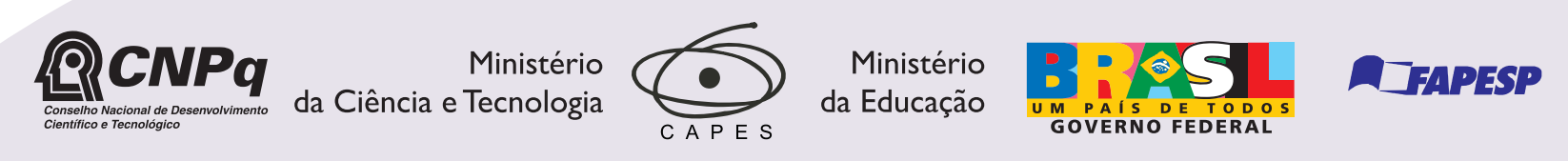

Institutional Sponsors

Scie/
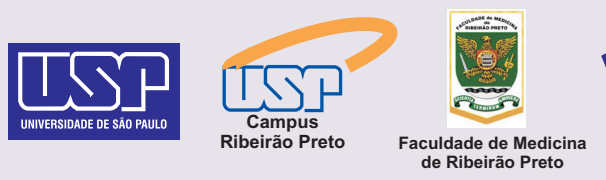

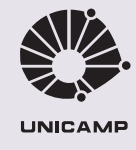

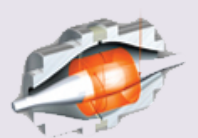

๑ SHIMADZu

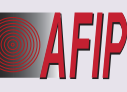

Associaçăa de Incentivo
à Pesquisa

plore High - Performance MS Orbitrap Technology analitica Thermo 


\title{
Effect of heat and moisture exchangers on the prevention of ventilator-associated pneumonia in critically ill patients
}

\author{
M. Auxiliadora-Martins ${ }^{1}$, M.G. Menegueti ${ }^{2}$, E.A. Nicolini ${ }^{1}$, G.C. Alkmim-Teixeira ${ }^{1}$, \\ F. Bellissimo-Rodrigues ${ }^{3}$, O.A. Martins-Filho ${ }^{4}$ and A. Basile-Filho ${ }^{1}$ \\ ${ }^{1}$ Divisão de Terapia Intensiva, Departamento de Cirurgia e Anatomia, Hospital das Clínicas, \\ Faculdade de Medicina de Ribeirão Preto, Universidade de São Paulo, Ribeirão Preto, SP, Brasil \\ ${ }^{2}$ Escola de Enfermagem de Ribeirão Preto, Universidade de São Paulo, Ribeirão Preto, SP, Brasil \\ ${ }^{3}$ Departamento de Medicina Social, Hospital das Clínicas, Faculdade de Medicina de Ribeirão Preto, \\ Universidade de São Paulo, Ribeirão Preto, SP, Brasil \\ ${ }^{4}$ Laboratório de Biomarcadores de Diagnóstico e Monitoração, Instituto René Rachou, \\ Fundação Oswaldo Cruz, Belo Horizonte, MG, Brasil
}

\begin{abstract}
Ventilator-associated pneumonia (VAP) remains one of the major causes of infection in the intensive care unit (ICU) and is associated with the length of hospital stay, duration of mechanical ventilation, and use of broad-spectrum antibiotics. We compared the frequency of VAP 10 months prior to (pre-intervention group) and 13 months after (post-intervention group) initiation of the use of a heat and moisture exchanger (HME) filter. This is a study with prospective before-and-after design performed in the ICU in a tertiary university hospital. Three hundred and fourteen patients were admitted to the ICU under mechanical ventilation, 168 of whom were included in group $\mathrm{HH}$ (heated humidifier) and 146 in group HME. The frequency of VAP per 1000 ventilator-days was similar for both the $\mathrm{HH}$ and $\mathrm{HME}$ groups (18.7 vs 17.4, respectively; $\mathrm{P}=0.97$ ). Duration of mechanical ventilation (11 vs 12 days, respectively; $P=0.48$ ) and length of ICU stay (11 vs 12 days, respectively; $P=0.39$ ) did not differ between the $\mathrm{HH}$ and HME groups. The chance of developing VAP was higher in patients with a longer ICU stay and longer duration of mechanical ventilation. This finding was similar when adjusted for the use of HME. The use of HME in intensive care did not reduce the incidence of VAP, the duration of mechanical ventilation, or the length of stay in the ICU in the study population.
\end{abstract}

Key words: Heat and moisture exchanger; Ventilator-associated pneumonia; Quality improvement; Nosocomial infection; Critically ill patients

\section{Introduction}

Hospital-acquired pneumonia remains as one of the main causes of infection in the intensive care unit (ICU) $(1,2)$ and is associated with the length of hospital stay $(1,3)$, duration of mechanical ventilation, and use of broad-spectrum antibiotics. This condition results in increased hospital costs $(1,2,4-6)$ and patient mortality $(3,6)$. This type of pneumonia occurs more frequently in patients who have been on mechanical ventilation for more than $48 \mathrm{~h}$, characterizing the ventilator-associated pneumonia (VAP). The mortality due to VAP varies between 24 and $50 \%$, reaching $76 \%$ in highrisk situations (7). Diagnosis is based on the appearance of a new or progressive pulmonary infiltrate accompanied by fever, leukocytosis, and purulent sputum (8).
The natural mechanisms of inspired air humidification and heating are suppressed during mechanical ventilation. Induced air heating and humidification can be achieved actively by using heated humidifiers $(\mathrm{HH})$, or passively, by means of heat and moisture exchangers (HME). Aspiration of the condensed water that is formed in the ventilator circuit as a consequence of air heating and humidification is one of the causes of VAP. The bacteria colonizing the patients themselves can proliferate in the condensate and return to the airways and lungs by inhalation of this contaminated material. Therefore, it is possible that the use of HME could contribute to preventing the onset of VAP with a positive impact on the reduction of the incidence of VAP. Various

Correspondence: M. Auxiliadora-Martins, Divisão de Terapia Intensiva, Departamento de Cirurgia e Anatomia, Hospital das Clínicas, FMRP, USP, Av. Bandeirantes, 3900, 14049-900 Ribeirão Preto, SP, Brasil. Fax: +55-16-3602-2439. E-mail: mamartins@hcrp.usp.br and/ormam_martins@hotmail.com

Received May 8, 2012. Accepted September 3, 2012. Available online October 15, 2012. Published December 17, 2012. 
controlled and randomized clinical studies have compared $\mathrm{HME}$ and $\mathrm{HH}$ with respect to the occurrence of VAP (9-12). However, data on their real benefit regarding VAP prevention remain inconclusive.

Data collected in our institution (1999-2009) have revealed an incidence of VAP per 1000 ventilator-days of 18.7 (Menegueti MG, Bellissimo-Rodrigues F, unpublished data). This high incidence has prompted the search for a type of intervention that could improve control of this infection. In this context, the aim of this study was to evaluate the impact of HME on the likelihood of critically ill patients developing VAP. The duration of mechanical ventilation, length of ICU stay, occurrence of adverse events, and overall mortality in the ICU were also investigated.

\section{Material and Methods}

This was a prospective study performed in the ICU of a tertiary care hospital associated with a public medical school and university. It is a 9-bed adult ICU that delivers intensive care to highly complex medical and surgical patients. All the patients admitted to the ICU with an expected length of stay greater than $48 \mathrm{~h}$ were considered eligible for the study. The present study was approved by the Research Ethics Committee of Hospital das Clínicas, Faculdade de Medicina de Ribeirão Preto, Universidade de São Paulo (Protocol No. 7076/2010). Written informed consent was obtained from all patients or from an appropriate surrogate when the patient was unable to provide the consent. This investigation consisted of a before-and-after study comparing the chance of acquiring VAP 10 months prior to (pre-intervention group) and 13 months (post-intervention group) after initiation of the use of an HME filter.

\section{Study population}

The study was conducted on 314 patients admitted to the ICU under mechanical ventilation, 168 of whom were included in group $\mathrm{HH}$ and 146 in group HME. Demographic and clinical data were collected from the medical records and physical examination of the patients. Organ dysfunction was assessed by Acute Physiology and Chronic Health Evaluation (APACHE) II score (13). All patients aged $>18$ years submitted to mechanical ventilation and admitted to the ICU between January 2009 and November 2010 were invited for inclusion in the study and were examined on a daily basis.

The HME hygroscopic filter device (Humid Vent ${ }^{\circledR}$ Filter Compact, Gibeck, Germany) was used for all the patients undergoing mechanical ventilation and admitted to the ICU, provided that there was no contraindication. The device was changed every $24 \mathrm{~h}$ according to manufacturer recommendations and the hospital guidelines for infection control. Patients were excluded from the study if they presented abundant thick secretion with or without blood, pulmonary hyperinflation, bulky bronchopleural fistula, body temperature lower than $32^{\circ} \mathrm{C}$, minute volume $>10 \mathrm{~L} / \mathrm{min}$, low respiratory muscle reserve, or significant impairment of the respiratory mechanics due to severe obstruction of the airways or acute respiratory distress syndrome and bronchospasm.

The HH was an MR410 Respiratory Humidifier (Fisher \& Paykel Healthcare Ltd., New Zealand). The ventilators consisted of microprocessed equipment (Savina or Evita XL, Drägermedical, USA, or Bird 8400, Tri-Bird Prod. Co., USA) operating in the mode consistent with the patient's underlying disease.

Identical measures for VAP prevention were established for both patient groups: no routine change of ventilator circuits, a semirecumbent body position, continuous enteral nutrition, oral wash with $2 \%$ clorhexidine $(14,15)$, respiratory physiotherapy, no verification of residual gastric volume, and no aspiration of subglottic secretions.

Daily visits were performed by the ICU staff accompanied by a member of the local committee for hospital infection control, with the purpose of establishing the VAP diagnosis and searching for any adverse events caused by hypercapnia and/or endotracheal tube obstruction by secretion. These procedures applied for VAP prevention as well as the antibiotics policy were under the responsibility of the same ICU staff and the hospital infection control members for both groups of patients. The diagnosis of pneumonia was based on the criteria of the Centers for Disease Control and Prevention (16). Pneumonia was considered to be VAP when it was diagnosed after $48 \mathrm{~h}$ of mechanical ventilation. Based on the time of onset of pneumonia, VAP can be further categorized into early (occurring within the first 4 days of mechanical ventilation) and late (occurring after day 4). Etiologically, late VAP is more frequently due to multidrugresistant pathogens and has a poorer prognosis than early VAP. In general, risk factors are the same (9).

The primary end point was to compare the VAP rate between the two groups. Secondary outcomes included duration of mechanical ventilation, length of ICU stay, occurrence of adverse events, and ICU overall mortality.

\section{Statistical analysis}

From 1999 to 2009, the VAP rate at the study ICU was 18.7 episodes per 1000 ventilator-days (Menegueti MG, Belissimo-Rodrigues $\mathrm{F}$, unpublished data). In order to achieve the sufficient power to detect a $60 \%$ reduction in VAP incidence, with $\alpha=5 \%$ and $\beta=20 \%$, the calculated sample size was 125 patients in each group. Considering the possible patient's drop out during the study, the sample size was increased to 168 in the $\mathrm{HH}$ group and to 146 in the HME group. Statistical analyses were performed using the SAS 9.2 program (SAS Institute Inc., SAS/STAT ${ }^{\circledR}$ User's Guide, Version 9.2, USA: SAS Institute Inc., 2008). Data are reported as median and range and were compared by the Mann-Whitney U-test. A P value lower than 0.05 was considered to be significant. A post hoc subgroup analysis 
was conducted by adjusting multiple logistic regression models with VAP as the dependent variable and age, gender, comorbidities, length of ICU stay, and duration of mechanical ventilation as independent variables.

\section{Results}

Of the 325 patients initially included, 11 (3.4\%) were ultimately excluded because the study protocol was not followed correctly ( 5 patients in the $\mathrm{HH}$ group and 6 in the HME group).

Overall, 314 patients participated in this investigation. They were divided into two groups, namely group $\mathrm{HH}$ ( $\mathrm{N}=168)$, which included patients that utilized $\mathrm{HH}$, and group HME $(\mathrm{N}=146)$, which consisted of patients that used HME.

Analysis of the clinical characteristics of the patients revealed that both groups had similar distribution in terms of age, gender, comorbidity, medical conditions that led to ICU admission, and APACHE II score, as summarized in Table 1. Respiratory failure, risk factors for developing VAP, and circulatory shock were also similar for the two groups.

During the study, 56 VAP events were diagnosed, 29 in the HH group (15 early VAP events) and 27 in the HME group (18 early VAP events). There were no reductions in VAP rates when groups $\mathrm{HH}$ and $\mathrm{HME}$ were compared. Moreover, the incidence of VAP per 1000 ventilator-days was similar in the $\mathrm{HH}$ and $\mathrm{HME}$ groups (18.7 vs 17.4; $\mathrm{P}=0.97$ ). There were no significant reductions in the incidence of VAP (either early or late VAP episodes) in the patients included in the HME group.

Most VAP episodes diagnosed [(43/56 (77\%)] were confirmed microbiologically, including 21 episodes in the $\mathrm{HH}$ group and 23 in the HME group. The microorganisms isolated are listed in Table 2.
Table 1. Demographic and clinical characteristics of the patients in the $\mathrm{HH}$ and $\mathrm{HME}$ groups.

\begin{tabular}{lcc}
\hline & $\begin{array}{c}\mathrm{HH} \text { group } \\
(\mathrm{N}=168)\end{array}$ & $\begin{array}{c}\mathrm{HME} \text { group } \\
(\mathrm{N}=146)\end{array}$ \\
\hline Characteristics & & \\
Gender (female) & $73(43 \%)$ & $65(44 \%)$ \\
Age (mean and range in years) & $56(15-89)$ & $52(17-87)$ \\
APACHE II score (mean and range) & $26(10-47)$ & $27(10-48)$ \\
Death risk (mean and range in \%) & $56(6-98)$ & $58(4-98)$ \\
Comorbidity & & \\
Diabetes mellitus & $21(12 \%)$ & $22(15 \%)$ \\
Renal failure & $35(21 \%)$ & $47(32 \%)$ \\
Coronary disease & $34(20 \%)$ & $16(11 \%)$ \\
COPD & $15(9 \%)$ & $3(2 \%)$ \\
Infectious diseases & $88(52 \%)$ & $75(51 \%)$ \\
Hypertension & $52(31 \%)$ & $38(26 \%)$ \\
Malignancy & $48(28 \%)$ & $34(23 \%)$ \\
Reason for ICU admission & & \\
Respiratory failure & $37(22 \%)$ & $25(17 \%)$ \\
Liver transplantation & $9(5 \%)$ & $10(7 \%)$ \\
Major surgery, postoperative & $10(6 \%)$ & $4(3 \%)$ \\
Shock & $67(40 \%)$ & $61(42 \%)$ \\
Severe sepsis & $10(6 \%)$ & $18(12 \%)$ \\
Cardiac arrest & $17(10 \%)$ & $12(8 \%)$ \\
Others & $18(11 \%)$ & $16(11 \%)$ \\
Risk factor during ICU stay & & \\
Tracheostomy & $59(35 \%)$ & $59(40 \%)$ \\
Inhibitors of gastric acid secretion & $67(40 \%)$ & $61(42 \%)$ \\
\hline
\end{tabular}

Data are reported as number of patients with percent in parentheses or as otherwise stated. $\mathrm{HH}=$ heated humidifier group; $\mathrm{HME}=$ heat and moisture exchanger group; COPD = chronic obstructive pulmonary disease.

Table 2. Microorganisms isolated from patients with VAP who received heated humidifiers $(\mathrm{HH})$ or heat and moisture exchangers (HME).

\begin{tabular}{|c|c|c|c|c|}
\hline \multirow[t]{2}{*}{ Microorganisms } & \multicolumn{2}{|c|}{$\mathrm{HH}$ group } & \multicolumn{2}{|c|}{ HME group } \\
\hline & Blood culture & $\begin{array}{c}\text { Tracheal aspirate or } \\
\text { bronchoscopy }\end{array}$ & Blood culture & $\begin{array}{c}\text { Tracheal aspirate or } \\
\text { bronchoscopy }\end{array}$ \\
\hline Enterococcus faecalis & 1 & - & - & - \\
\hline Coagulase-negative Staphylococcus & 2 & - & 2 & - \\
\hline Staphylococcus aureus & 2 & - & 1 & 1 \\
\hline Acinetobacter baumannii & 1 & 7 & 2 & 9 \\
\hline Corynebacterium & - & - & 1 & 1 \\
\hline Enterobacter cloacae & 1 & - & - & - \\
\hline Klebsiella pneumoniae & - & - & - & 1 \\
\hline Pseudomonas aeruginosa & 2 & 6 & 2 & 5 \\
\hline Serratia marcescens & - & 1 & - & - \\
\hline Stenotrophomonas maltophilia & - & 1 & - & 2 \\
\hline Fungus & - & 2 & - & 1 \\
\hline Total & 9 & 17 & 8 & 20 \\
\hline
\end{tabular}

Data are reported as number of positive results. VAP = ventilator-associated pneumonia. 
Table 3. Chances of developing VAP in patients who received heated humidifiers $(\mathrm{HH})$ or heat and moisture exchangers (HME).

\begin{tabular}{lcccc}
\hline & VAP & No VAP & OR crude $(95 \% \mathrm{Cl})$ & OR adjusted $(95 \% \mathrm{Cl})$ \\
\hline $\mathrm{HH}$ & $29(9.24)$ & $139(44.27)$ & 1 & 1 \\
$\mathrm{HME}$ & $27(8.60)$ & $119(37.90)$ & $1.09(0.61-1.94)$ & $1.08(0.57-2.06)$ \\
\hline
\end{tabular}

Data are reported as number of VAP cases with percent in parentheses. VAP = ventilator-associated pneumonia. OR crude = comparison between groups. OR adjusted = comparison between groups adjusted for gender, age, chronic diseases, length of stay, and duration of mechanical ventilation.

Table 4. Duration of mechanical ventilation in the study population.

\begin{tabular}{lcccc}
\hline Mechanical ventilation (days) & VAP & No VAP & OR crude $(95 \% \mathrm{Cl})$ & OR adjusted $(95 \% \mathrm{Cl})$ \\
\hline Up to 10 & $16(5.10)$ & $180(57.32)$ & 1 & 1 \\
11 to 30 & $31(9.87)$ & $67(21.34)$ & $5.20(2.68-10.12)$ & $5.21(2.68-10.14)$ \\
31 to 50 & $6(1.91)$ & $8(2.55)$ & $8.43(2.6-27.33)$ & $8.32(2.56-27.09)$ \\
$>50$ & $3(0.96)$ & $3(0.96)$ & $11.25(2.1-60.35)$ & $11.37(2.11-61.19)$ \\
\hline
\end{tabular}

Data are reported as number of VAP cases with percent in parentheses. VAP = ventilator-associated pneumonia. OR crude = comparison between groups. OR adjusted = comparison between groups adjusted for gender, age, chronic diseases and length of stay.

Duration of mechanical ventilation (11 vs 12 days; $\mathrm{P}=$ 0.48 ) and length of ICU stay (11 vs 12 days; $P=0.39$ ) did not differ between the $\mathrm{HH}$ and HME groups. The ICU overall mortality was similar for both groups (55.3 vs $55.4 \%$ ), and the death risk calculated by the APACHE II prognostic index was 56 and $58 \%$ for the $\mathrm{HH}$ and $\mathrm{HME}$ groups, respectively. No adverse event was identified in either group.

The chance of developing VAP did not differ between the study groups, thereby demonstrating the ineffectiveness of $\mathrm{HME}$ as a preventive measure, with a crude odds ratio of $1.09(95 \% \mathrm{Cl}=0.61-1.94)$. After adjustment for gender, age, comorbidities, duration of mechanical ventilation, and length of stay in the ICU, the likelihood of developing VAP again did not differ between the study groups, with an adjusted odds ratio of $1.08(95 \% \mathrm{Cl}=0.57-2.06$; Table 3$)$.

Our results also showed that there were no differences between groups with respect to duration of mechanical ventilation and length of stay in the ICU after adjustment for $\mathrm{HH}$ and $\mathrm{HME}$. As for the number of days that patients were kept under mechanical ventilation, the chances of developing VAP was about five $(\mathrm{OR}=5.2 ; 95 \% \mathrm{Cl}=2.68-10.12)$, eight $(\mathrm{OR}=8.43 ; 95 \% \mathrm{Cl}=2.6-27.33)$, and eleven $(\mathrm{OR}=11.25$; $95 \% \mathrm{IC}=2.1-60.35)$ times higher in patients submitted to mechanical ventilation for 11-30, 31-50, and over 50 days compared to individuals who remained under mechanical ventilation for less than 11 days. This result was the same after adjustment for utilization of a filter, as shown in Table 4. Regarding the length of stay in the ICU, the probability of developing VAP was about six $(\mathrm{OR}=5.92 ; 95 \% \mathrm{Cl}=$
2.99-11.74), eight $(\mathrm{OR}=8.38 ; 95 \% \mathrm{Cl}=2.61-26.94)$, and twelve $(\mathrm{OR}=12.57 ; 95 \% \mathrm{Cl}=2.32-68.15)$ times higher for patients staying for $11-30,31-50$, and over 50 days in the ICU compared to those who stayed for less than 11 days. These data were also the same after adjustment for filter utilization.

\section{Discussion}

Literature studies have been contradictory in relation to the impact of HME on VAP prevention. A meta-analysis (9) including nine studies and 1378 patients revealed that the use of HME reduces VAP rates particularly in individuals submitted to mechanical ventilation for over 7 days (relative risk $=0.7 ; 95 \% \mathrm{Cl}=0.50-0.94)$. However, previous nonrandomized investigations that were not included in this meta-analysis had found significantly lower VAP rates with the use of $\mathrm{HH}$ compared to $\mathrm{HME}(17,18)$. Two other randomized studies reported a nonsignificant difference in VAP rates $(10,11)$, and a randomized investigation including 120 patients described a lower VAP incidence with $\mathrm{HH}$ in patients under mechanical ventilation for over 5 days (15.69 vs 39.62\%; $P=0.006$ ) (19). A later meta-analysis published by Siempos et al. (12), including 13 randomized clinical assays representing 2580 patients, did not detect any differences between $\mathrm{HME}$ and $\mathrm{HH}$ in terms of VAP incidence, mortality in the ICU, length of stay in the ICU, duration of mechanical ventilation, or episodes of airway obstruction. 
Our data indicate that the use of HME was not enough to prevent VAP in ICU patients. This is corroborated by the fact that there were no differences between the study groups for any of the parameters evaluated, including VAP incidence, duration of mechanical ventilation, length of stay in the ICU, and global mortality rate. On the other hand, filter utilization led to optimization of the work of the nursing staff since application of the filter eliminated the need to open the circuit and discard the water that accumulated in the respirator. There was also a fall in the number of technical problems with the respirator sensors, which contributed to reduced expenditure with maintenance services. Regarding HME expenses in our institution, the average daily cost per patient was US $\$ 6.48$ vs US $\$ 5.9$ for $\mathrm{HH}$ and $\mathrm{HME}$, respectively. Despite the lower HME cost, also demonstrated in other studies (10), it is noteworthy that this device is not exempt from risks. The most severe complication is endotracheal tube obstruction by secretion. This is due to diminished moisture production, especially when a larger minute volume is employed, which is common to all commercially available instruments to a higher or lesser extent $(17,20)$. In our case, obstruction of the endotracheal tube with need for re-intubation did not occur, but this is an adverse effect that has been described in other studies (21-28). Another concern is the increase in dead space with hypercapnia and airway resistance, which are mainly dependent on the internal volume of the filter and accumulation of liquids, respectively (29-31). In the present study, there was no record of hypercapnia or increased airway resistance requiring HME withdrawal.

Here, the fact that there was no reduction in the rate of VAP in the presence of HME compared to $\mathrm{HH}$ is in agreement with various published randomized investigations (10-12,17-19). A study by Kirton et al. (21) evaluating 280 trauma victims reported a lower VAP incidence for HME. A possible explanation for the fact that our results were different from those of Kirton et al. would be the severity of the patients (APACHE II >25) included herein associated with their several comorbidities. Other aspects that could influence our results refer to the filters employed in the present

\section{References}

1. Vincent JL, Bihari DJ, Suter PM, Bruining HA, White J, Nicolas-Chanoin $\mathrm{MH}$, et al. The prevalence of nosocomial infection in intensive care units in Europe. Results of the European Prevalence of Infection in Intensive Care (EPIC) Study. EPIC International Advisory Committee. JAMA 1995; 274: 639-644.

2. Rello J, Ollendorf DA, Oster G, Vera-Llonch M, Bellm L, Redman R, et al. Epidemiology and outcomes of ventilatorassociated pneumonia in a large US database. Chest 2002; 122: 2115-2121.

3. Bercault N, Boulain T. Mortality rate attributable to ventilatorassociated nosocomial pneumonia in an adult intensive care investigation, which were provided by different suppliers from those of other studies, as well as the frequency of filter exchange and the diagnostic criteria for VAP. Moreover, the studied populations differed between investigations (21). Nevertheless, various clinical studies have demonstrated that longer HME use, from 24-48 h up to 4 or 7 days, is not related to an increased risk of VAP (32-34).

Our results agree with the proposed VAP pathophysiology in the sense that inoculation of bacteria into the lungs is believed to usually occur through the extraluminal source, while it is thought to take place by the intraluminal route only sporadically $(35,36)$.

The present study has some limitations. First, direct assessment of the heating and humidification of the inspired air was not carried out, since we relied on manufacturer specifications. Secondly, VAP was not diagnosed via an invasive procedure for all patients; in some individuals, only clinical and radiological criteria were employed for diagnosis. Finally, our study did not include a randomized trial.

It may be suggested that both $\mathrm{HH}$ and $\mathrm{HME}$ can be utilized in the ICU, without any significant impact on VAP incidence. Considering hospital costs and lack of contraindications, the use of HME should be considered as an alternative humidification method for patients submitted to mechanical ventilation. Further studies are necessary for clarification of the actual effect of this device on VAP prevention.

Our results have demonstrated that the use of HME in an intensive care unit did not reduce the incidence of VAP, the duration of mechanical ventilation, or the length of stay in the ICU in the study population.

\section{Acknowledgments}

We are thankful to Davi Casale Aragon for assistance with the statistical analysis. Research supported by Fundação de Amparo ao Ensino, Pesquisa e Assistência (FAEPA), Hospital das Clínicas and Faculdade de Medicina de Ribeirão Preto-USP. unit: a prospective case-control study. Crit Care Med 2001; 29: 2303-2309.

4. Chen YY, Wang FD, Liu CY, Chou P. Incidence rate and variable cost of nosocomial infections in different types of intensive care units. Infect Control Hosp Epidemiol 2009; 30: $39-46$.

5. Warren DK, Shukla SJ, Olsen MA, Kollef MH, Hollenbeak CS, Cox MJ, et al. Outcome and attributable cost of ventilator-associated pneumonia among intensive care unit patients in a suburban medical center. Crit Care Med 2003; 31: 1312-1317.

6. Safdar N, Dezfulian C, Collard HR, Saint S. Clinical and eco- 
nomic consequences of ventilator-associated pneumonia: a systematic review. Crit Care Med 2005; 33: 2184-2193.

7. Meduri GU. Diagnosis and differential diagnosis of ventilatorassociated pneumonia. Clin Chest Med 1995; 16: 61-93.

8. Rello J, Paiva JA, Baraibar J, Barcenilla F, Bodi M, Castander $D$, et al. International Conference for the Development of Consensus on the Diagnosis and Treatment of VentilatorAssociated Pneumonia. Chest 2001; 120: 955-970.

9. Kola A, Eckmanns T, Gastmeier P. Efficacy of heat and moisture exchangers in preventing ventilator-associated pneumonia: meta-analysis of randomized controlled trials. Intensive Care Med 2005; 31: 5-11.

10. Lacherade JC, Auburtin M, Cerf C, Van de Louw A, Soufir $\mathrm{L}$, Rebufat $\mathrm{Y}$, et al. Impact of humidification systems on ventilator-associated pneumonia: a randomized multicenter trial. Am J Respir Crit Care Med 2005; 172: 1276-1282.

11. Boots RJ, George N, Faoagali JL, Druery J, Dean K, Heller RF. Double-heater-wire circuits and heat-and-moisture exchangers and the risk of ventilator-associated pneumonia. Crit Care Med 2006; 34: 687-693

12. Siempos II, Vardakas KZ, Kopterides P, Falagas ME. Impact of passive humidification on clinical outcomes of mechanically ventilated patients: a meta-analysis of randomized controlled trials. Crit Care Med 2007; 35: 2843-2851.

13. Knaus WA, Draper EA, Wagner DP, Zimmerman JE. APACHE II: a severity of disease classification system. Crit Care Med 1985; 13: 818-829.

14. Bellissimo-Rodrigues F, Bellissimo-Rodrigues WT, Viana JM, Teixeira GC, Nicolini E, Auxiliadora-Martins M, et al. Effectiveness of oral rinse with chlorhexidine in preventing nosocomial respiratory tract infections among intensive care unit patients. Infect Control Hosp Epidemiol 2009; 30: 952-958.

15. Koeman M, van der Ven AJ, Hak E, Joore HC, Kaasjager K, de Smet AG, et al. Oral decontamination with chlorhexidine reduces the incidence of ventilator-associated pneumonia. Am J Respir Crit Care Med 2006; 173: 1348-1355.

16. Tablan OC, Anderson LJ, Besser R, Bridges C, Hajjeh R. Guidelines for preventing health-care-associated pneumonia, 2003: recommendations of CDC and the Healthcare Infection Control Practices Advisory Committee. MMWR Recomm Rep 2004; 53: 1-36.

17. Cohen IL, Fein IA. Norepinephrine therapy in septic shock. Crit Care Med 1988; 16: 206-207.

18. Blin F, Fraisse F, Chauveau P, Lahilaire P, Boulet E, Bouhaddi $R$, et al. Incidence of nosocomial pneumonias among 1788 ventilated patients in 6 ICU according to the type of humidification used. Intensive Care Med 1996; 22: S324.

19. Lorente L, Lecuona M, Jimenez A, Mora ML, Sierra A. Ventilator-associated pneumonia using a heated humidifier or a heat and moisture exchanger: a randomized controlled trial [ISRCTN88724583]. Crit Care 2006; 10: R116.

20. Doyle A, Joshi M, Frank P, Craven T, Moondi P, Young P. A change in humidification system can eliminate endotracheal tube occlusion. J Crit Care 2011; 26: 637 e1-4.

21. Kirton OC, DeHaven B, Morgan J, Morejon O, Civetta J. A prospective, randomized comparison of an in-line heat moisture exchange filter and heated wire humidifiers: rates of ventilator-associated early-onset (community-acquired) or late-onset (hospital-acquired) pneumonia and incidence of endotracheal tube occlusion. Chest 1997; 112: 1055-1059.
22. Martin C, Perrin G, Gevaudan MJ, Saux P, Gouin F. Heat and moisture exchangers and vaporizing humidifiers in the intensive care unit. Chest 1990; 97: 144-149.

23. Roustan JP, Kienlen J, Aubas P, Aubas S, du Cailar J. Comparison of hydrophobic heat and moisture exchangers with heated humidifier during prolonged mechanical ventilation. Intensive Care Med 1992; 18: 97-100.

24. Dreyfuss D, Djedaini K, Gros I, Mier L, Le Bourdelles G, Cohen $\mathrm{Y}$, et al. Mechanical ventilation with heated humidifiers or heat and moisture exchangers: effects on patient colonization and incidence of nosocomial pneumonia. Am J Respir Crit Care Med 1995; 151: 986-992.

25. Boots RJ, Howe S, George N, Harris FM, Faoagali J. Clinical utility of hygroscopic heat and moisture exchangers in intensive care patients. Crit Care Med 1997; 25: 1707-1712.

26. Hurni JM, Feihl F, Lazor R, Leuenberger P, Perret C. Safety of combined heat and moisture exchanger filters in long-term mechanical ventilation. Chest 1997; 111: 686-691.

27. Kollef MH, Shapiro SD, Boyd V, Silver P, Von Harz B, Trovillion E, et al. A randomized clinical trial comparing an extended-use hygroscopic condenser humidifier with heated-water humidification in mechanically ventilated patients. Chest 1998; 113: 759-767.

28. Memish ZA, Oni GA, Djazmati W, Cunningham G, Mah MW. $A$ randomized clinical trial to compare the effects of a heat and moisture exchanger with a heated humidifying system on the occurrence rate of ventilator-associated pneumonia. Am J Infect Control 2001; 29: 301-305.

29. Briassoulis G, Paraschou D, Hatzis T. Hypercapnia due to a heat and moisture exchanger. Intensive Care Med 2000; 26: 147.

30. Wilkes AR. Heat and moisture exchangers and breathing system filters: their use in anaesthesia and intensive care. Part 1 - history, principles and efficiency. Anaesthesia 2011; 66: 31-39.

31. Wilkes AR. Heat and moisture exchangers and breathing system filters: their use in anaesthesia and intensive care. Part 2 - practical use, including problems, and their use with paediatric patients. Anaesthesia 2011; 66: 40-51.

32. Markowicz P, Ricard JD, Dreyfuss D, Mier L, Brun P, Coste F, et al. Safety, efficacy, and cost-effectiveness of mechanical ventilation with humidifying filters changed every 48 hours: a prospective, randomized study. Crit Care Med 2000; 28: 665-671.

33. Thomachot L, Boisson C, Arnaud S, Michelet $P$, Cambon S, Martin C. Changing heat and moisture exchangers after 96 hours rather than after 24 hours: a clinical and microbiological evaluation. Crit Care Med 2000; 28: 714-720.

34. Thomachot L, Leone M, Razzouk K, Antonini F, Vialet R, Martin C. Randomized clinical trial of extended use of a hydrophobic condenser humidifier: 1 vs. 7 days. Crit Care Med 2002; 30: 232-237.

35. Safdar N, Crnich CJ, Maki DG. The pathogenesis of ventilator-associated pneumonia: its relevance to developing effective strategies for prevention. Respir Care 2005; 50: 725-739.

36. Cardenosa Cendrero JA, Sole-Violan J, Bordes BA, Noguera CJ, Arroyo FJ, Saavedra SP, et al. Role of different routes of tracheal colonization in the development of pneumonia in patients receiving mechanical ventilation. Chest 1999; 116: 462-470. 